\title{
Attitudes about science and conceptual physics learning in university introductory physics courses
}

\author{
Marina Milner-Bolotin, ${ }^{1}$ Tetyana Antimirova, ${ }^{2, *}$ Andrea Noack, ${ }^{3}$ and Anna Petrov ${ }^{4}$ \\ ${ }^{1}$ Department of Curriculum and Pedagogy, University of British Columbia, Vancouver, British Columbia, V6T 1Z4, Canada \\ ${ }^{2}$ Department of Physics, Ryerson University, Toronto, Ontario, M5B 2K3, Canada \\ ${ }^{3}$ Department of Sociology, Ryerson University, Toronto, Ontario, M5B 2K3, Canada \\ ${ }^{4}$ Department of Chemistry and Biology, Ryerson University, Toronto, Ontario, M5B 2K3, Canada \\ (Received 22 December 2010; published 23 September 2011)
}

\begin{abstract}
This paper examines the results of the repeated administration of the Colorado Learning Attitudes about Science Survey (CLASS) in a large introductory physics course at a midsize, metropolitan Canadian university. We compare the results to those obtained previously in comparable courses at the University of British Columbia (Canada) and the University of Colorado (U.S.). Atypically, students in this study exhibited a positive shift in their attitudes about science over the semester. The change in students' attitudes across the term appears to be moderated by their educational background-specifically, whether they had taken grade 12 physics or not. The correlation between students' attitudes and their conceptual knowledge also appears to be influenced by students' educational background. The results have pedagogical implications for instructors of introductory college and university physics and potentially for other science courses.
\end{abstract}

DOI: 10.1103/PhysRevSTPER.7.020107

PACS numbers: 01.40.Fk

\section{INTRODUCTION}

During the past 50 years Western societies have become substantially more reliant on science and technology. Paradoxically, public attitudes toward science have been steadily on the decline during the same time [1] with a brief exception of the period following World War II and the Sputnik era [2]. Even the space race during the Cold War was inadequate to attract a sufficient number of North American students, especially women and minorities, into science [3-8]. Physics, unfortunately, is not an exception but rather an example of how students' attitudes about the discipline might negatively affect their achievement [9-14]. Students' negative attitudes about physics and limited interest in science more generally have translated into low student enrollments in high school and consequently in university physics courses leading toward degrees in physical sciences. This has resulted in fewer students pursuing and persevering in physics-related careers during their undergraduate degree $[9,10,15-18]$.

Students' attitudes about science are shaped by their real-world experiences, their parents, peers, teachers, and the media. These attitudes are often well established long before students enroll in postsecondary science courses [19-21]. Attitudes about science influence students'

\footnotetext{
*Corresponding author. antimiro@ryerson.ca
}

Published by the American Physical Society under the terms of the Creative Commons Attribution 3.0 License. Further distribution of this work must maintain attribution to the author(s) and the published article's title, journal citation, and DOI. expectations about university science courses, how they learn science, and their perceptions of science careers $[10,16,22,23]$. Several studies note, however, that students' attitudes about science in general and their attitudes about "school science" might differ [1]. Gray et al. [24] probed the difference between students' personal beliefs and what they thought a physicist would believe. Regardless of their high school experience, students who have not yet taken physics in college have a rather accurate idea of what physicists believe about physics. These ideas were largely unaffected by their college physics instruction, whereas the students' personal beliefs about physics differed depending on their high school physics experience and college physics courses in which they chose to enroll.

Many studies have attempted to measure the relationship between attitudes about science and student achievement [12-14,25-29]. Several different patterns have emerged in various studies. While causal relationships are difficult if not impossible to establish, it is clear that there is a correlation between students' attitudes about science and achievement in science courses $[12,14]$. This correlation is especially prominent among general science students, compared to those students who self-select into undergraduate engineering courses [27]. For instance, Perkins and her collaborators [14] found students' beliefs about science when entering introductory university physics courses correlated significantly with their conceptual science learning. Okpala and Onocha [30] found attitudes about science to be one of the nine significant correlates of achievement in physics in the final year of a high school physics course in Nigeria. In a study comparing American and Lebanese physics students, Halloun [31] found that 
"students' views about science expressed in the broad cognitive domain correlate better with the course achievement" (p. 29). On the other hand, Wilson and collaborators [27] did not find a correlation between students' attitudes towards science and their achievement. This might be explained by the fact that the students they surveyed were engineering students who had self-selected into science courses as a result of their interest and attitudes about science and engineering.

Studies of the relationships between students' attitudes about science and their academic achievement are not limited to high school or undergraduate student populations. For example, Singh and Mason [26] found that graduate students' attitudes about science can significantly influence their problem-solving approaches. Similar studies have been conducted in other countries [1]. The generalization of the results must be done very carefully due to the variability of defining "attitudes about science" and the variability in students' populations.

Helping physics learners to acquire expertlike behaviors and attitudes has long been one of the central goals of physics teaching. Improving students' attitudes might have a potential positive effect on student science learning. A more comprehensive understanding of students' attitudes about science may thus provide insight into how physics instructors might shape their teaching practices in order to maximize student learning and help them to develop a more expertlike approach to science problem solving that is consistent with expertlike attitudes about science [32-37].

In this research project, we investigate the relationship between undergraduate first year science students' attitudes about science, their conceptual physics learning, and the change in these characteristics across a semester when the students were enrolled in an introductory calculus-based physics course for science majors in a midsize, metropolitan Canadian university with very diverse student population.

\section{RESEARCH METHODOLOGY}

The project was conducted Fall 2008 at a midsize $(\sim 25000$ students $)$ Canadian university located in an urban metropolis. Because of its location and reputation, this university attracts a diverse student population in terms of race and ethnicity and place of birth [38]. All science students are required to take a calculus-based introductory physics course. Upon enrollment, the students were randomly assigned to one of three sections of the introductory physics course. The two sections that participated in this study were taught by equally experienced female physics professors who are committed to best teaching practices, and who employ a variety of interactive teaching methods. The course runs for 13 weeks, with two two-hour weekly lectures supplemented by a one-hour weekly problemsolving tutorial or recitation session led by two graduate teaching assistants with limited physics teaching training.
There is no course prerequisite, although in general about $60 \%$ of the students in the introductory classes have previously taken a grade 12 physics course or its equivalent. Modified peer instruction was used in conjunction with clickers to increase active participation during the lectures. In addition, the students had four in-class, more substantial small-group activities [39]. For these activities, the students were presented with different scenarios and were asked to choose the correct one and develop an argument to support their choice. The instructors also used in-class demonstrations exploiting the cognitive conflict between student prior knowledge and the experimental results [40]. To extend the learning beyond the classroom, the students were required to complete five Mastering Physics tutorials or assignments consisting of both not-for-credit skill builder tutorial-type problems and for-credit homework problems. The students were also required to complete a homework assignment based on video analysis of a demonstration. The Colorado Learning Attitudes about Science Survey (CLASS) [11,12,41] and the Force Concept Inventory (FCI) [42] were administered twice in each class-during the 2nd and the 12th weeks of the term. The survey data were collected and tabulated by a researcher from outside of the physics department, such that the course professors did not have access to students' information before the course was concluded. Student participation in the study was strictly voluntary and anonymous; students received no incentives for completing CLASS surveys. This research was reviewed and approved by the university's Research Ethics Board.

The Colorado Learning Attitudes about Science Survey $[11,12,41]$ is a validated tool that allows physics instructors and physics education researchers to evaluate student attitudes about science. It is premised on making distinctions between the science beliefs of experts compared to the beliefs of novices [35,43]. The CLASS contains 42 Likert-style statements grouped into eight categories: "personal interest," "real-world connections," "conceptual connections," "sense making and/or effort," "problem solving sophistication," "problem solving confidence," "problem solving general," and "applied conceptual understanding." 1 These categories represent empirically determined groupings of statements based on students' responses to the survey and demonstrate that students have many consistent ideas about learning physics and problem solving [11].

The Force Concept Inventory [42,45] is a popular instrument for measuring student understanding of the basic Newtonian mechanics that have traditionally been the focus of introductory physics courses. Although there are some concerns about the limited validity of the tool

\footnotetext{
${ }^{1}$ More details about the contents of each of these categories of CLASS instrument and their calculation is available (see Ref. [44]).
} 
[46,47], the vast majority of data on the application of the Force Concept Inventory collected over the past 20 years suggests that student performance on this instrument provides valuable information on their conceptual learning and correlates positively with other instruments $[46,48]$.

Only the students who completed both CLASS surveys, both FCI tests, provided information about completion of the grade 12 physics course, as well as signed an informed consent form were included in the analysis below. ${ }^{2} \mathrm{~A}$ total of 155 students, out of 258 potential participants at the beginning of the course (before the drop date), met these criteria, for a response rate of $60 \% .^{3}$ Among this group, $58 \%$ of students were women, $37 \%$ were visible minorities, and $45 \%$ were born outside of Canada. Among the students who were born outside of Canada, the largest group (about 1/4) were from the Middle East (e.g., Iran, Pakistan) and the next largest group (about 15\%) was from East Asia (e.g., China, Hong Kong, South Korea). About 2/3 of students $(68 \%)$ had previously taken a grade 12 physics course or its equivalent; among those students slightly more than half $(56 \%)$ reported getting an A grade in the course, with $35 \%$ reporting a B grade, and the remainder reporting a lower grade.

\section{RESULTS AND DISCUSSION}

\section{A. Changing attitudes about science}

Many students see the study of physics as something which is disconnected from the real world. They perceive it as a science consisting of isolated facts that occasionally connect though a web of incomprehensible formulas. Following the typical interpretation of CLASS results, the term novices is used to describe individuals who view physics as a collection of isolated facts and formulas that must be memorized, and who feel that these pieces of information have little connection to the real world $[14,49,50]$. The term experts is applied to individuals whose thinking about physics is congruent with the thinking of physicists, who see physics as a coherent framework of interconnected concepts and equations which describe physical phenomena and which are verified through experiments. Pollock [13] found that in introductory physics classes with traditional instruction methods, students' "expertlike" beliefs typically decline by about $10 \%$. Perkins et al. [12] make similar claims about the effect of introductory physics courses and students' attitudes. The data we collected appear to deviate from this typical

\footnotetext{
${ }^{2}$ CLASS also has a "screening" question that tests to see if students are reading carefully and not selecting random answers. Students who did not answer this question correctly were excluded from the analysis.

${ }^{3}$ This response rate is conservative, as it is based on the number of students who were enrolled in the courses at the beginning of the term. Approximately $20 \%$ of the students dropped the course, and as such did not have the opportunity to complete the tests in week 12 of the term.
}

pattern. Figure 1 shows the overall results for each of the CLASS categories in week 2 (pretest) and week 12 (posttest). The results for each category are plotted based on the average percentage of favorable (expert) attitudes by the average percentage of unfavorable (novice) attitudes. In general, a move towards the upper left corner of the graph shows an increase in favorable attitudes and a decline in unfavorable attitudes; conversely, a move towards the bottom right corner of the graph shows a decrease in favorable attitudes and an increase in unfavorable attitudes.

In almost all of the CLASS categories, students moved towards more expertlike attitudes over the course of the semester. The two exceptions are the categories of problem solving-general and sense making and/or effort, suggesting that students still experience difficulty making sense of physics, which affects their problem-solving skills.

When only favorable attitudes are considered, these results are also atypical. Table I shows CLASS results from this study compared to published results from another Canadian university and an American university. On average, students from the University of British Columbia (UBC), Vancouver (Canada) and University of Colorado, Boulder (U.S.) became increasingly confused about physics and its connection to the real world as they progressed through their introductory physics courses, and finished the semester with less favorable attitudes than when they began. In this study, students had a small positive shift towards more favorable (expert) attitudes in all categories except sense making and/or effort. Paired $t$ tests of the change between favorable attitudes show that the only statistically significant difference between pretest and posttest attitudes was for the category real-world connections. There were no significant changes in unfavorable attitudes.

In this study, all of the shifts were positive, but the only statistically significant result was an increase in real-world connections. Notably, however, there is no significant decline in attitudes across the course, as was found in the Colorado studies. While it is impossible to determine what particular demographic, curriculum, or pedagogy features in our study may contribute to the somewhat unusual results we observed, we have identified several factors that distinguish our study from the other two studies. In both this study and that at the University of British Columbia, the CLASS was anonymous, voluntary, and had no incentives for completion, while students who completed the CLASS in Colorado received participation marks. The students who took part in this study had a slightly lower average initial FCI score $(-8 \%)$ than the students at the University of British Columbia and the University of Colorado. In addition, both of the Canadian universities are demographically similar in that they are ethnically diverse, metropolitan postsecondary institutions. These demographic factors that were beyond the researchers' control may explain why there are differences between 


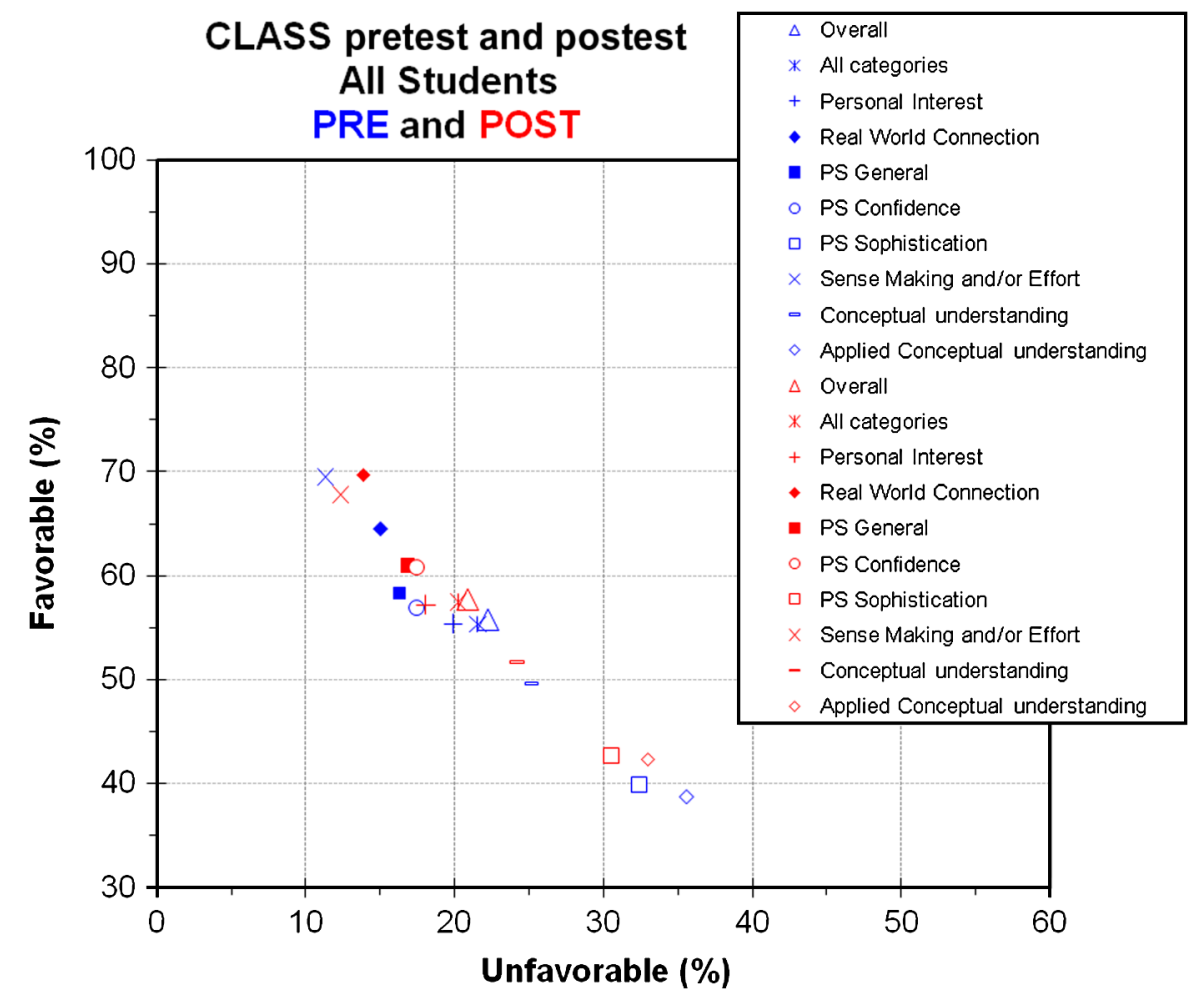

FIG. 1 (color online). CLASS results in week 2 and week 12 of an introductory physics course. Week 2 results are shown in blue, while week 12 results are shown in red. PS, problem solving.

students at this university and University of Colorado, but not necessarily UBC.

The introductory physics courses that we studied were also different from the traditional introductory physics course. The two course instructors collaborated extensively throughout the term, creating a coherent and cohesive learning environment for both course sections. Although the course was still lecture based, the instructors strived to achieve the high degree of interactive engagement that permeated all of the course components, including lectures, tutorials, homework assignments, and evaluations.
This collaboration resulted in the use of various interactive teaching methods and tools, such as peer instruction [51], collaborative group work [39,52], interactive lecture experiments, an online homework system [53], computer simulations [54], and Logger Pro's video analysis software [55]. We speculate that these technology-enhanced pedagogies may have allowed students to gain a better understanding of physical phenomena and possibly contributed to the increased favorable view of physics by making lectures relate directly to real-life student experiences and thus more appealing. In addition, the course instructors

TABLE I. Comparison of week 2 and week 12 CLASS results with those from University of British Columbia (UBC) and the University of Colorado at Boulder. Average percentage of favorable responses (agree with experts) is shown, with the standard error of the mean in parentheses; differences that are statistically significant at the $p<0.05$ level are shown in bold. UBC and University of Colorado results from Refs. [12,25].

\begin{tabular}{|c|c|c|c|c|c|c|c|c|c|}
\hline \multirow[b]{2}{*}{ CLASS category } & \multicolumn{3}{|c|}{ Colorado $(n=397)$} & \multicolumn{3}{|c|}{$\mathrm{UBC}(n=91)$} & \multicolumn{3}{|c|}{ This study $(n=155)$} \\
\hline & Pretest & Posttest & Shift & Pretest & Posttest & Shift & Pretest & Posttest & Shift \\
\hline Overall & $65(1)$ & $59(1)$ & -6 & $48(2)$ & $46(2)$ & -2 & $55.8(1)$ & $57.7(1)$ & +2 \\
\hline Personal interest & $67(1)$ & $56(2)$ & -11 & $40(3)$ & $36(3)$ & -4 & $55.4(2)$ & $57.3(2)$ & +2 \\
\hline Real world connections & $72(1)$ & $65(2)$ & -7 & $50(4)$ & $46(4)$ & -4 & $64.5(3)$ & $69.7(2)$ & +5 \\
\hline Problem solving general & $71(1)$ & $58(1)$ & -13 & $50(3)$ & $45(3)$ & -5 & $58.3(2)$ & $61.0(2)$ & +3 \\
\hline Problem solving confidence & $73(1)$ & $58(2)$ & -15 & $51(4)$ & $45(3)$ & -6 & $56.9(2)$ & $60.8(2)$ & +4 \\
\hline Problem solving sophistication & $61(1)$ & $46(2)$ & -15 & $34(3)$ & $28(3)$ & -6 & $39.9(2)$ & $42.7(2)$ & +3 \\
\hline Sense making and/or effort & $73(1)$ & $63(1)$ & $-\mathbf{1 0}$ & $63(3)$ & $56(3)$ & -7 & $69.5(2)$ & $67.8(2)$ & -2 \\
\hline Conceptual connections & $63(1)$ & $55(1)$ & -8 & $43(3)$ & $41(3)$ & -2 & $49.6(2)$ & $51.7(2)$ & +2 \\
\hline Applied conceptual understanding & $53(1)$ & $47(1)$ & -6 & $34(2)$ & $32(2)$ & -2 & $38.7(2)$ & $42.3(2)$ & +4 \\
\hline
\end{tabular}


were fully aware that the students in the introductory physics course had mixed physics backgrounds and worked to create a supportive and nurturing learning environment for all students.

The premise that interactive teaching contributes to student science learning is based on a body of research that began to emerge in the late 1980s early 1990 s $[49,56]$. While Dewey $[57,58]$ and other prominent educators emphasized the importance of active learning decades earlier [59-62], it was not until the last quarter of the 20th century that science educators developed readily available, validated, reliable, and easy to administer instruments that could measure student science learning. In addition, technological advances such as automated scanning systems, electronic response systems, and online surveys made the analysis of these tests feasible. In addition to the use of interactive teaching methods, it is likely that other unidentified factors also contributed to the observed positive shift in students' attitude, a phenomenon which warrants further investigation.

\section{B. Effect of grade 12 physics on students' attitudes about science}

As anticipated, we found that students who had previously taken grade 12 physics had more favorable and expertlike attitudes about science than those who had not taken a grade 12 physics course. Table II shows the differences between students who had or had not taken grade 12 physics.

These results suggest that there is a significant interaction between students' prior physics knowledge and changes in their attitudes about science. Having previously taken a grade 12 physics course appears to moderate students' attitude change over the course of the semester. In particular, students without a formal high school background knowledge of physics have a relatively durable set of attitudes about science that persist throughout the term.
In contrast, students with more advanced physics knowledge at the beginning of the course may find that their attitudes improve as they learn more. Since introductory university physics covers much of the material that is covered in grade 12 physics, students who have a second opportunity to engage with this material may be able to integrate the physics concepts into the existing conceptual framework in a more expertlike way. Students who are engaging with this material for the first time might still perceive it as a series of disconnected facts [23]. The effect of high school physics courses (or the lack of thereof) on the success in introductory physics has been widely discussed in the literature [63]. Although there is no consensus about how much student success in college or university physics courses is influenced by their high school physics courses experience, there is no doubt that the background physics knowledge of incoming students plays an important role in their further science education.

A unique opportunity to study the impact of student high school physics preparation on their success in undergraduate physics courses took place in Ontario (Canada) during the 2002-2004 academic years. The academic year of 2002-2003 was the last year when Ontario high schools offered grade 13 . As a result, grade 12 and grade 13 students competed for university spaces in the summer of 2003. Slavin [64] investigated the factors affecting the success of the double cohort undergraduate physics students during 2003-2004 academic year. During this period, the dropout rates in introductory university physics courses plummeted from $16 \%$ before the double cohort to $9 \%$ during the two years of the double cohort entering the university system before bouncing back to $16 \%$ in 2005-2006. Slavin [65] found that one of the major factors in the reduced university physics dropout rates during the years that followed the double cohort was an improved student work ethic as a result of facing stiff competition for university entrance and consequently better science preparation.

TABLE II. Relationship between taking grade 12 physics and favorable attitudes about physics in week 2 and week 12 . Average percentage of favorable responses (agree with experts) is shown, with the standard error of the mean in parentheses. Differences that are statistically significant at the $p<0.05$ level are shown in bold.

\begin{tabular}{|c|c|c|c|c|c|c|}
\hline CLASS category & $\begin{array}{l}\text { Without grade } 12 \\
\qquad(n=42)\end{array}$ & $\begin{array}{l}\text { Week } 2 \\
\text { With grade } 12 \\
\quad(n=90)\end{array}$ & Difference & $\begin{array}{l}\text { Without grade } 12 \\
\quad(n=42)\end{array}$ & $\begin{array}{l}\text { Week } 12 \\
\text { With grade } 12 \\
\quad(n=90)\end{array}$ & Difference \\
\hline Overall & $48(2)$ & $58(2)$ & $+\mathbf{1 0}$ & $49(2)$ & $62(2)$ & +13 \\
\hline Personal interest & $46(4)$ & $58(3)$ & +12 & $41(4)$ & $64(3)$ & +23 \\
\hline Real world connection & $57(5)$ & $68(3)$ & +11 & $55(5)$ & $78(3)$ & +23 \\
\hline Problem solving general & $49(4)$ & $61(2)$ & +12 & $46(3)$ & $67(2)$ & +21 \\
\hline Problem solving confidence & $43(5)$ & $60(3)$ & $+\mathbf{1 7}$ & $45(4)$ & $68(3)$ & +23 \\
\hline Problem solving sophistication & $27(3)$ & $44(3)$ & $+\mathbf{1 7}$ & $25(3)$ & $49(3)$ & +24 \\
\hline Sense making and/or effort & $64(4)$ & $71(2)$ & +7 & $59(4)$ & $73(2)$ & +14 \\
\hline Conceptual connections & $38(4)$ & $54(3)$ & +16 & $43(3)$ & $56(3)$ & +13 \\
\hline Applied conceptual understanding & $29(3)$ & $42(2)$ & +13 & $34(3)$ & $46(3)$ & +12 \\
\hline
\end{tabular}




\section{Relationship between attitudes about science and conceptual understanding}

A key question this study explored was the relationship between students' attitudes about science and how much they learned in introductory physics courses. Overall students' conceptual understanding increased across the course, but the absolute gain was larger for students who had not completed grade 12 physics. Table III shows the week 2 and week 12 FCI scores for students overall. There is a significant improvement in FCI scores for the population overall, and for students who did not complete grade 12 physics, but not for the subgroup of student who did complete grade 12 physics. Grade 12 physics covers much of the material on the FCI; this is reflected in higher initial FCI scores for students who had previously taken grade 12 physics. Hake's gain formula provides a better comparison between the groups, however, since it shows the proportion of previously unknown material that students have learned [66]. Students with a grade 12 physics background learned $25 \%$ of the previously unknown material, whereas students without a grade 12 physics background learned $31 \%$ of the previously unknown material (referred to as the Hake index $\langle g\rangle[66]$ ). It is important to mention that the concepts measured by FCI included a small portion of the concepts learned in the course; thus, FCI measured a limited number of course concepts.

Table IV shows the correlation between students' favorable (expertlike) attitudes and their score on the FCI. Given the moderating effects of grade 12 physics on students' attitudes, the results shown are divided by students' educational background. At the beginning of the course, the strongest correlations between conceptual understanding and attitudes about science are for those students who did not take grade 12 physics. This likely reflects the process of educational self-selection; students with unfavorable attitudes towards physics also have little conceptual understanding of physics, because they have chosen not to pursue physics-related courses. The only category that is not significantly correlated is problem solving confidence. For students who did take grade 12 physics, attitudes about science appear to have less of an effect on conceptual understanding. The effect of students' attitudes towards science on their learning may also be moderated by prior education.

Interestingly, the opposite effect appears at the end of the course. For students without grade 12 physics, attitudes

TABLE III. Pretest and posttest FCI scores, by grade 12 physics background. Differences that are statistically significant at the $p<0.05$ level are shown in bold.

\begin{tabular}{|c|c|c|c|c|c|c|c|c|c|}
\hline & \multicolumn{3}{|c|}{ All students ${ }^{\mathrm{a}}(n=155)$} & \multicolumn{3}{|c|}{ With grade $12(n=90)$} & \multicolumn{3}{|c|}{ Without grade $12(n=42)$} \\
\hline & Week 2 & Week 12 & $\begin{array}{c}\text { Difference } \\
\langle g\rangle\end{array}$ & Week 2 & Week 12 & $\begin{array}{c}\text { Difference } \\
\langle g\rangle\end{array}$ & Week 2 & Week 12 & $\begin{array}{c}\text { Difference } \\
\langle g\rangle\end{array}$ \\
\hline FCI $(\%)$ score & 35.4 & 51.6 & $\begin{array}{r}+16.2 \\
0.25\end{array}$ & 39.4 & 54.8 & $\begin{array}{r}+15.4 \\
0.25\end{array}$ & 25.0 & 48.0 & $\begin{array}{r}+23.0 \\
\mathbf{0 . 3 1}\end{array}$ \\
\hline
\end{tabular}

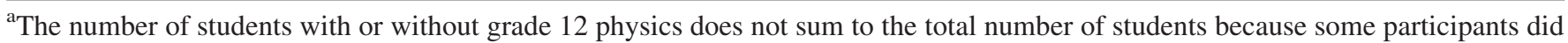
not indicate whether they had taken grade 12 physics.

TABLE IV. Correlations (Pearson's $r$ ) between favorable attitudes about physics and FCI score for students with and without grade 12 physics in week 2 and week 12. Statistically significant results at the $p<0.05$ level are shown in bold.

\begin{tabular}{|c|c|c|c|c|c|c|}
\hline CLASS category & $\begin{array}{l}\text { All students } \\
\quad(n=155)\end{array}$ & $\begin{array}{c}\text { Week } 2 \\
\text { Without grade } 12 \\
(n=42)\end{array}$ & $\begin{array}{l}\text { With grade } 12 \\
\quad(n=90)\end{array}$ & $\begin{array}{l}\text { All students }{ }^{\mathrm{a}} \\
\quad(n=155)\end{array}$ & $\begin{array}{c}\text { Week } 12 \\
\text { Without grade } 12 \\
(n=42)\end{array}$ & $\begin{array}{l}\text { With grade } 12 \\
\quad(n=90)\end{array}$ \\
\hline Overall & 0.294 & 0.560 & 0.191 & 0.258 & 0.292 & 0.258 \\
\hline Personal interest & 0.095 & 0.471 & -0.058 & 0.142 & 0.137 & 0.116 \\
\hline Real world connection & 0.105 & 0.452 & 0.014 & 0.127 & 0.270 & 0.050 \\
\hline Problem solving general & 0.269 & 0.430 & 0.176 & 0.252 & 0.185 & 0.308 \\
\hline Problem solving confidence & 0.221 & 0.084 & 0.155 & 0.253 & 0.176 & 0.311 \\
\hline Problem solving sophistication & 0.384 & 0.455 & 0.286 & 0.250 & 0.080 & 0.293 \\
\hline Sense making and/or effort & 0.083 & 0.343 & 0.015 & 0.097 & 0.231 & 0.010 \\
\hline Conceptual connections & 0.301 & 0.405 & 0.263 & 0.204 & 0.151 & 0.215 \\
\hline Applied conceptual understanding & 0.322 & 0.325 & 0.259 & 0.179 & 0.102 & 0.215 \\
\hline $\begin{array}{l}\text { Critical value of Pearson's } r \text { for } \\
\quad p<0.05 \text { (two-tailed) }\end{array}$ & 0.158 & 0.304 & 0.208 & 0.158 & 0.304 & 0.208 \\
\hline
\end{tabular}

${ }^{\mathrm{a}}$ The number of students with or without grade 12 physics does not sum to the total number of students because some participants did not indicate whether they had taken grade 12 physics. 
seem to have little effect on their conceptual knowledge. In effect, these students are at the same place that their peers, who had taken grade 12 physics, were at the beginning of the semester. In contrast, there was some association between favorable (expertlike) attitudes about physics and FCI scores for students who had previously taken grade 12 physics in many categories. Recall that students with grade 12 physics had a much larger gain in favorable attitudes compared to students without grade 12 physics. This gain in favorable attitudes is positively correlated with their high scores on the FCI at the end of the course.

A similar pattern in correlations to that in Table IV exists between the percentage of unfavorable (novicelike) attitudes and FCI scores in week 2, though the correlations are negative. At the conclusion of the course, there are no statistically significant correlations between the percentage of unfavorable attitudes and FCI scores for either group, with the one exception of a weak correlation between problem solving sophistication and FCI score for students who had taken grade 12 physics.

These results show the importance of considering students' prior subject-specific background in assessing the relationship between science attitudes and knowledge gained as a result of taking an undergraduate science (physics) course. It cannot be determined from these data whether or not favorable (expertlike) attitudes lead to a deeper conceptual understanding or whether deeper conceptual understanding leads students to adopt more favorable attitudes. Further investigation is required to answer this question and, in our view, the results will have substantial implications for undergraduate science teaching and learning.

\section{CONCLUSIONS}

In this study, we found results that were atypical compared to previous studies investigating students' attitudes about science in introductory physics courses. In this sample, students' attitudes about science remained constant or became more expertlike over the course of the term instead of declining. It is beyond the scope of this study to establish whether these differences can be attributed to the demographic characteristics of our specimen that were beyond the researchers' control, to the coherent and cohesive use of the variety of interactive technology-enhanced teaching methods, to the careful alignment between the learning goals and the evaluation methods, or due to the supportive and nurturing learning environment created by two female professors teaching the course.

A subanalysis shows that students who had taken grade 12 physics had a much larger increase in favorable (expertlike) attitudes over the course of the term. Similarly, the correlations between students' favorable attitudes and their conceptual knowledge were moderated by whether they had taken grade 12 physics. At the beginning of the term, students who had not taken grade 12 physics had a stronger correlation between favorable attitudes and FCI scores, whereas at the end of the term this correlation was stronger for students who had taken grade 12 physics.

These results of the study have substantial implications for introductory physics teaching. In part, the study provides evidence to suggest that students with substantially less educational backgrounds (without grade 12 physics) might be better served in a separate classroom or by offering them a bridging course before attempting the introductory undergraduate physics course. In view of these findings, the current trend to combine in one course the students with extremely varying educational backgrounds needs to be reconsidered. At the very least, instructors should be aware of the differences between students with different educational backgrounds and tailor their instruction accordingly. These results are limited by the sample size and the investigation of students at a single university. We encourage other researchers to undertake similar investigations and analyses to develop a more detailed understanding of the changes in students' attitudes about science during introductory physics courses and the relationships between these attitudes and their conceptual knowledge.

\section{ACKNOWLEDGMENTS}

We are grateful for the assistance of Sergio OrtizPenarredonda in collecting, entering, and coding these data, and for the support of a SSHRC Ryerson Internal Grant and the Ryerson University Undergraduate Research Assistant Program.
[1] J. Osborne, S. Simon, and S. Collins, Attitudes towards science: A review of the literature and its implications, Int. J. Sci. Educ. 25, 1049 (2003).

[2] G. M. Pion and M.W. Lipsey, Public attitudes toward science and technology: What have the surveys told us?, Publ. Opin. Q. 45, 303 (1981).
[3] K. R. Sopka et al., Making Contributions: An Historical Overview of Women's Role in Physics (American Association of Physics Teachers, College Park, MD, 1983).

[4] P. Dickson, Sputnik: The Shock of the Century (Walker Publishing Co., New York, 2001). 
[5] G. Moritz, From Sputnik to NDEA: The changing role of science during the Cold War, 1999 [http://codex23.com/ gtexts/college/papers/j3.html].

[6] N. Frelindich, From Sputnik to TIMSS: Reforms in science education make headway despite setbacks: More time is needed for widespread classroom changes, Harv. Educ. Lett. 14 (1998) [http://www.project2061.org/ publications/articles/articles/harvard.htm].

[7] S. E. Nichols et al., in International Handbook of Science Education, edited by B. J. Fraser and K. G. Tobin (Kluwer, Dordrecht, 1997), p. 1.

[8] National Research Council, Women in Science and Engineering: Increasing Their Numbers in the 1990s. A Statement on Policy and Strategy (National Academies Press, Washington DC, 1991).

[9] V.L. Dickinson and L. B. Flick, Beating the system: Course structure and student strategies in traditional introductory undergraduate physics course, School Sci. Math. 98, 238 (1998).

[10] E.F. Redish, J. M. Saul, and R. N. Steinberg, Student expectations in introductory physics, Am. J. Phys. 66, 212 (1998).

[11] W. K. Adams et al., New instrument for measuring student beliefs about physics and learning physics: The Colorado Learning Attitudes about Science Survey, Phys. Rev. ST Phys. Educ. Res. 2, 010101 (2006).

[12] K. K. Perkins et al., Towards characterizing the relationship between students' self-reported interest in and their surveyed beliefs about physics, in Proceedings of the Physics Education Research Conference, Salt Lake City, Utah, 2005, edited by P. Heron, L. McCullough, and J. Marx (American Institute of Physics, New York, 2005), Vol. 818.

[13] S. J. Pollock, No single cause: Learning gains, student attitudes, and the impacts of multiple effective reforms, in Proceedings of the Physics Education Research Conference, Sacramento, California, 2004, edited by J. Marx, P. Heron, and S. Franklin (American Institute of Physics, New York, 2004), Vol. 790, p. 137.

[14] K. K. Perkins et al., Correlating student beliefs with student learning using the Colorado Learning Attitudes about Science Survey, in Proceedings of the Physics Education Research Conference Sacramento, California, 2004 (Ref. [13]).

[15] E. Seymour and N. M. Hewitt, Talking about Leaving: Why Undergraduates Leave the Sciences (Westview Press, Boulder, CO, 1997).

[16] E.F. Redish, J. M. Saul, and R. N. Steinberg, Student expectations in introductory physics, Am. J. Phys. 66, 212 (1998).

[17] S. V. Etten, G. Freebern, and M. Pressley, College students' beliefs about exam preparation, Contemp. Educ. Psychol. 22, 192 (1997).

[18] D. Fortun, Creating an atmosphere in physics for the motivation of Asian students, Phys. Educ. 29, 74 (1994).

[19] T. R. Koballa, Jr., in Learning Science in the Schools, edited by S. Glyyn and R. Duit (Lawrence Erlbaum Associates, Mahwah, NJ, 1995).

[20] G. M. Breakwell and S. Beardsell, Gender, parental and peer influences upon science attitudes and activities, Publ. Understand. Sci. 1, 183 (1992).
[21] R.E. Yager and J.E. Penick, Public attitude toward science and science education, Bull Sci. Tech. Soc. 6, 339 (1986).

[22] A. A. diSessa, in The Handbook of Education and Human Development: New Models of Learning, Teaching and Schooling, edited by D.R. Olson and N. Torrance (Blackwell, Malden, MA, 1996), Vol. 1, p. 709.

[23] A. A. diSessa, in Constructivism in the Computer Age, edited by G. Forman and P. B. Pufall (Lawrence Erlbaum Associates, Hillsdale, NJ, 1988), Vol. 1, p. 49.

[24] K. E. Gray et al., Students know what physicists believe, but they don't agree: A study using the CLASS survey, Phys. Rev. ST Phys. Educ. Res. 4, 1 (2008).

[25] R. Moll and M. Milner-Bolotin, The effect of interactive lecture experiments on student academic achievement and attitudes towards physics, Can. J. Phys. 87, 917 (2009).

[26] C. Singh and A. Mason, Physics graduate students' attitudes and approaches to problem solving, in Proceedings of the Physics Education Research Conference, Ann Arbor, Michigan, 2009, edited by M. Sabella, C. Henderson, and C. Singh (American Institute of Physics, New York, 2009), Vol. 1179, p. 273.

[27] V. L. Wilson, C. Ackerman, and C. Malave, Cross-time attitudes, concept formation, and achievement in college freshman physics, J. Res. Sci. Teach. 37, 1112 (2000).

[28] J. A. Middleton and P. A. Spanias, Motivation for achievement in mathematics: findings, generalizations, and criticisms of the research, J. Res. Math. Educ. 30, 65 (1999).

[29] P.D. Morell and N. G. Lederman, Students' attitudes toward school and classroom science: Are they independent phenomena?, School Sci. Math. 98, 76 (1998).

[30] P. Okpala and C. Onocha, Student factors as correlates of achievement in physics, Phys. Educ. 23, 361 (1988).

[31] I. A. Halloun, in Student Views About Science: A Comparative Survey (Lebanese University Educational Research Center, Beirut, 2001), p. 69 [http://modeling .asu.edu/R\&E/IHalloun/VASS-2001Monograph.pdf].

[32] D. Bransford, A.L. Brown, and R. R. Cocking, How People Learn: Brain, Mind, Experience, and School (National Academies Press, Washington, DC, 2002).

[33] J. Discenna, A Study of Knowledge Structure of Expert, Intermediate and Novice Subjects in the Domain of Physics (Western Michigan University, Kalamazoo, MI, 1998 , p. 47.

[34] D. Andre and G. Fernand, Sherlock Holmes-An expert's view of expertise, Br. J. Psychol. 99, 109 (2008).

[35] P. B. Kohl and N. D. Finkelstein, Expert and novice use of multiple representations during physics problem solving, in Proceedings of the Physics Education Research Conference, Greensboro, NC, 2007, edited by L. Hsu, C. Henderson, and L. McCullough (American Institute of Physics, New York, 2007), Vol. 951, p. 132.

[36] Z. Hrepic, D. A. Zollman, and N. S. Rebello, Comparing students' and experts' understanding of the content of a lecture, J. Sci. Educ. Tech. 16, 213 (2007).

[37] J.D. Slotta, M. T.H. Chi, and E. Joram, Assessing students' misclassifications of physics concepts: An ontological basis for conceptual change, Cogn. Instr. 13, 373 (1995). 
[38] T. Antimirova, A. Noack, and M. Milner-Bolotin, The effect of classroom diversity on conceptual learning in physics, in Proceedings of the Physics Education Research Conference, Ann Arbor, Michigan, 2009, edited by M. Sabella, C. Singh and C. Henderson (Ref. [26]), Vol. 1176, p. 77.

[39] C.S. Kalman, M. Milner-Bolotin, and T. Antimirova, Comparison of the effectiveness of collaborative groups and peer instruction in a large introductory physics course for science majors, Can. J. Phys. 88, 325 (2010).

[40] M. Limon, On the cognitive conflict as instructional strategy for conceptual change: A critical appraisal, Learn. Instr. 11, 357 (2001).

[41] W. K. Adams, K. K. Perkins, M. Dubson et al., The design and validation of the Colorado Learning Attitudes about Science Survey, in Proceedings of the Physics Education Research Conference, Sacramento, 2004, edited by J. Marx (Ref. [13]).

[42] D. Hestenes, M. Wells, and G. Swackhamer, Force Concept Inventory, Phys. Teach. 30, 141 (1992).

[43] D. Winter et al., Novice instructors and student-centered instruction: Identifying and addressing obstacles to learning in the college science laboratory, J. Scholar. Teach. Learn. 2, 14 (2001).

[44] http://cosmos.colorado.edu/phet/survey/CLASS/

[45] D. Huffman and P. Heller, What does the force concept inventory actually measure?, Phys. Teach. 33, 138 (1995).

[46] R. K. Thornton et al., Comparing the force and motion conceptual evaluation and the force concept inventory, Phys. Rev. ST Phys. Educ. Res. 5, 010105 (2009).

[47] R. K. Thornton and D. R. Sokoloff, Assessing student learning of Newton's laws: The force and motion conceptual evaluation and the evaluation of active learning laboratory and lecture curricula, Am. J. Phys. 66, 338 (1998).

[48] A. Savinainen and P. Scott, Using the Force Concept Inventory to monitor student learning and to plan teaching, Phys. Educ. 37, 53 (2002).

[49] A. B. Arons, Teaching Introductory Physics (John Wiley and Sons, New York, 1997).

[50] C.S. Kalman, Successful Science and Engineering Teaching: Theoretical and Learning Perspectives (Springer, Secaucus, NJ, 2008).
[51] E. Mazur, Peer Instruction: User's Manual (Prentice Hall, Upper Saddle River, NJ, 1997).

[52] C.S. Kalman et al., Promoting conceptual change using collaborative groups in quantitative gateway courses, Am. J. Phys. 67, S45 (1999).

[53] D. Pritchard www.masteringphysics.com.

[54] K. Perkins et al., PhET: Interactive simulations for teaching and learning physics, Phys. Teach. 44, 18 (2006).

[55] T. Antimirova and M. Milner-Bolotin, A brief introduction to video analysis, Phys. Canada 65, 74 (2009).

[56] E.F. Redish, Teaching Physics with the Physics Suite (Wiley, New York, 2003).

[57] J. Dewey, Experience and Education (Simon and Schuster, New York, 1938).

[58] J. Dewey, The School and Society \& The Child and the Curriculum (University of Chicago Press, Chicago, 1943).

[59] A. L. Brown, Design experiments: Theoretical and methodological challenges in creating complex interventions in classroom settings, J. Learn. Sci. 2, 141 (1992).

[60] A.S. Bayer, Collaborative Apprenticeship Learning: Language and Thinking Across the Curriculum K-12 (Mayfield Publishing, Mountain View, CA, 1990).

[61] M. Cole, in Culture, Communication and Cognition, edited by J. V. Wertsch (Cambridge University Press, Cambridge, England, 1985), Vol. 1, p. 146.

[62] L. Vygotsky, Mind in Society: The Development of Higher Psychological Processes (Harvard University, Cambridge, MA, 1978).

[63] P. M. Sadler, Success in introductory college physics: The role of high school preparation, Sci. Educ. 85, 111 (2001).

[64] A. Slavin, Factors affecting student drop out from the university introductory physics course, including the anomaly of the Ontario double cohort, Phys. Canada 64, 149 (2008).

[65] A. Slavin, Factors affecting student drop out from the university introductory physics course, including the anomaly of the Ontario double cohort, Can. J. Phys. 86, 839 (2008).

[66] R. R. Hake, Interactive-engagement versus traditional methods: A six-thousand-student survey of mechanics test data for introductory physics courses, Am. J. Phys. 66, 64 (1998). 